\title{
Erratum to: Differences in quality of life of hemodialysis patients between dialysis centers
}

\author{
Albert H. A. Mazairac • Muriel P. C. Grooteman - Peter J. Blankestijn • \\ E. Lars Penne • Neelke C. van der Weerd • Claire H. den Hoedt • \\ Marinus A. van den Dorpel • Erik Buskens • Menso J. Nubé • Piet M. ter Wee • \\ G. Ardine de Wit $\cdot$ Michiel L. Bots
}

Published online: 23 July 2011

(C) Springer Science+Business Media B.V. 2011

\section{Erratum to: Qual Life Res}

DOI 10.1007/s11136-011-9942-3

The fourth author's family name was incorrect in the original publication. It is correct in this erratum.

The online version of the original article can be found under doi:10.1007/s11136-011-9942-3.

\footnotetext{
A. H. A. Mazairac - P. J. Blankestijn · E. L. Penne .

N. C. van der Weerd . C. H. den Hoedt

Department of Nephrology, University Medical Center Utrecht,

Utrecht, The Netherlands

M. P. C. Grooteman - E. L. Penne - N. C. van der Weerd .

M. J. Nubé · P. M. ter Wee

Department of Nephrology, VU Medical Center, Amsterdam,

The Netherlands

M. P. C. Grooteman · M. J. Nubé · P. M. ter Wee Institute for Cardiovascular Research VU Medical Center (ICaR-VU), VU Medical Center, Amsterdam, The Netherlands

C. H. den Hoedt - M. A. van den Dorpel

Department of Internal Medicine, Maasstad Hospital, Rotterdam,

The Netherlands
}

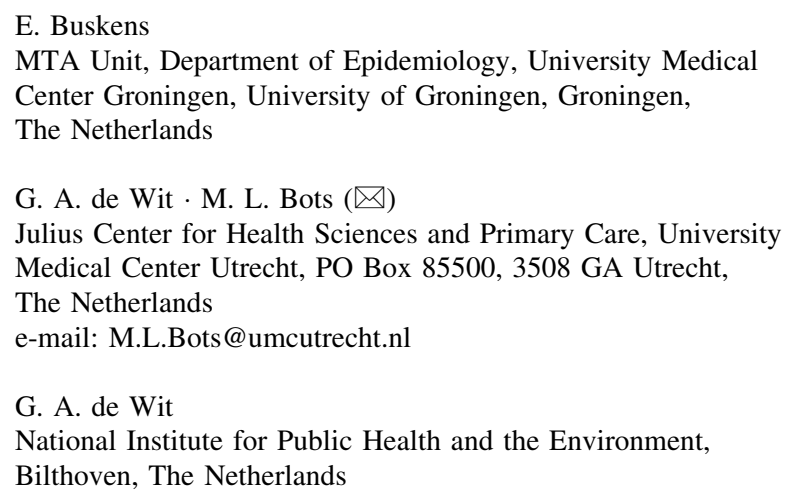

National Institute for Public Health and the Environment, Bilthoven, The Netherlands 